ORIGINAL ARTICLE

\title{
Economic implications of multiple births: inpatient hospital costs in the first 5 years of life
}

\author{
J Henderson, C Hockley, S Petrou, M Goldacre, L Davidson
}

Arch Dis Child Fetal Neonatal Ed 2004;89:F542-F545. doi: 10.1136/adc.2003.043851

See end of article for authors' affiliations ....................

Correspondence to: J Henderson, National Perinatal Epidemiology Unit, Old Road Campus, University of Oxford, Old Road, Headington, Oxford OX3 7LF, UK: jane.henderson@perinat. ox.ac.uk

Accepted 2 February 2004

Objectives: To estimate long term health service costs for hospital stays associated with singleton, twin, and higher order multiple births up to 5 years of age.

Design: Costs from specialty based data from the English Department of Health's NHS Trust Financial Returns were applied to admissions recorded in the Oxford record linkage study during 1970-1993.

Setting: Oxfordshire and West Berkshire, United Kingdom.

Subjects: A total of 276897 children, of whom 270428 were singletons, 6284 were twins, and 185 were higher order multiple births.

Main outcome measures: Duration of hospital admissions during the first 5 years of life. Costs, expressed in $£$ sterling and valued at 1998-1999 prices, of hospital inpatient services.

Results: The total duration of hospital admissions for twins and triplets were respectively twice and eight times that for singletons, once duration of life had been taken into account. Inpatient costs were significantly higher for multiple births than for singletons, with the cost differences concentrated in the first year of life. Over the first 5 years of life, the adjusted mean cost was estimated at $£ 1532$ (95\% confidence interval (CI) £1516 to £1548) for singletons, £3826 (95\% $£$ (3724 to £3929) for twins, and £8156 (95\%Cl £7559 to £8754) for higher order multiple births ( $p<0.0001)$.

Conclusions: Multiple births contribute disproportionately to hospital inpatient costs, especially during the children's first year of life.

O ver the last 20 years there has been an increasing trend in the number of multiple births in developed nations, particularly rates of triplets and higher order multiple births. ${ }^{12}$ In England and Wales, rates of triplets and higher order multiple births increased from 0.15 sets per thousand maternities in 1980 to 0.41 per 1000 maternities in 1994. ${ }^{1}$ These trends have also been reported in many other European countries and the United States. ${ }^{23}$

The economic implications for health services of the increase in multiple births are considerable. ${ }^{4-8}$ This is principally because of the high rates of prematurity associated with multiple births. ${ }^{8}$ Babies born preterm have significantly higher rates of morbidity and mortality, and costs are inversely related to gestational age at birth. ${ }^{9-11}$ A systematic review of long term costs of preterm birth and low birth weight found economic consequences not only to the health sector, but also to special education services, social services, families, and informal carers. ${ }^{11}$ The authors of the systematic review also noted the variable methodological quality of much of the literature on this topic, most of which adopted a narrow focus on short term health service costs.

Much of the literature on premature and low birthweight babies is also relevant to multiple births as they are generally preterm and low birth weight. Recent work using the Oxford record linkage study (ORLS) dataset shows that the factor with the greatest influence on health service costs during the first 5 years of life is gestational age at birth. ${ }^{12}$

However, costs of delivering and caring for a triplet or higher order multiple birth may or may not be higher than that of a singleton of the same gestation. In addition, little is known of the longer term hospital costs incurred by triplets or higher order multiple births. This study aimed to test the null hypothesis that long term inpatient costs do not differ significantly between singletons, twins, and higher order multiple births during the first 5 years of life.

\section{METHODS}

\section{Oxford record linkage study}

This study used data from the ORLS. This is a collection of linked, anonymised records of birth registrations, death certificates, and statistical abstracts of NHS hospital inpatient and day case admissions for a region of southern England. ${ }^{13}$ Data collection began in 1966 in Oxfordshire and West Berkshire, and, from 1975, increased its population coverage to include six of the eight districts of the former Oxford Region and, from 1984, the whole of the former Oxford Region. The ORLS had its own data collection systems for maternity and perinatal data until 1989 which covered Oxfordshire and West Berkshire only. Thereafter, data were derived from maternity Hospital Episodes Statistics for the relevant geographical area. Hospital data collection ceased in 1999.

\section{Study population}

The study population included all children born to women who both lived and delivered in Oxfordshire or West Berkshire during the period 1 January 1970 to 31 December 1993. Before 1970, much of the relevant perinatal information was missing; a delivery cut off point of 31 December 1993 was required for follow up to cover the first five years of life. Between 1970 and 1993, about 6\% of births to residents of Oxfordshire and West Berkshire took place outside of these two areas. These births were not included in the analyses. In addition, hospital admissions occurring outside the ORLS area were not available in the ORLS database and were therefore outside the scope of this study.

\section{Use of hospital services}

For each child, a record of inpatient service use between birth and 5 years of age was compiled. Data extracted from the ORLS included the number of babies delivered, date of each 


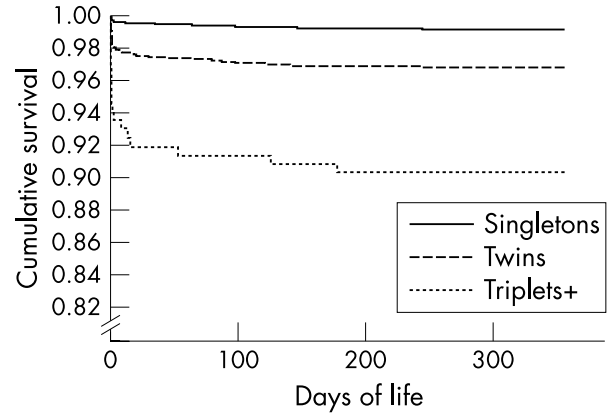

Figure 1 Singletons, twins, and triplets: survival to 1 year.

hospital admission, the duration of hospital stay, specialty on admission, and number of babies in that delivery. Each day case admission was counted as a full 24 hour period for the purposes of this study. A readmission was defined as being any hospital admission after the birth admission. If a baby was admitted directly to neonatal care after birth, this was counted as part of the birth admission. Total time spent in hospital was calculated for each child by summing the lengths of stay of each child's successive admissions. In addition, estimates of days in hospital were calculated for all children who were alive at the start of the period of life of interest (initial birth admission, consecutive years of life, first 5 years), with censoring for deaths. Children who were not readmitted to hospital at all during the first five years of life were included in the denominator in the calculation of means.

\section{Hospital service costs}

Inpatient costs were calculated for each hospital admission by multiplying the length of stay by the per diem cost of the respective specialty. The specialty based per diem costs were based on the English Department of Health's NHS Trust Financial Returns (TFR2) for 1997-1998 and 1998-1999, which had been averaged over these two financial years to eliminate any random fluctuation in the data. These returns incorporate short run current average revenue costs, plus revenue and capital overheads, and are widely accepted as reliable indicators of hospital service costs. ${ }^{14}$ For hospital records with an unknown or incorrect specialty code, the per diem medical or surgical cost was applied, depending on the approximate ORLS code range. All costs are expressed in constant $£$ sterling (1998-1999 prices) using the NHS Hospital and Community Health Services pay and price deflators provided by the English Department of Health.

\section{Statistical analysis}

The number of deaths over the first five years of life among live births was examined using Kaplan-Meier analysis. The log rank test was used to compare survival in singleton, twin, and higher order multiple births.

The total duration of hospital admissions, including the initial birth admission, during the first 5 years of life was compared in singletons, twins, and higher order multiple births using a multivariate negative binomial regression. ${ }^{15}$ Data on all children were incorporated into this analysis. Relative rates and 95\% confidence intervals for the number of days in hospital were calculated after adjustment for duration of life.

Cost differences between singletons, twins, and higher order multiple births that occurred over the first five years, as well as in each of the first five years of life, were tested using multiple linear regression, including only children alive at the start of each period in cost estimates. Costs are reported per child rather than per "set" of twins or triplets. The size of the study sample (276 897) was sufficiently large to expect robust parameter estimates, and therefore, despite the skewed nature of the data, alternative methods such as bootstrapping techniques were not applied. ${ }^{16}$

For all statistical analyses, differences were considered significant if $\mathrm{p}$ values were 0.001 or less. This cut off was selected both because multiple comparisons were being made and because in such a large dataset even a small difference tends to be significant. Analyses were performed with a microcomputer using SAS software (version 8.2; SAS Institute Inc, Cary, North Carolina, USA) and SPSS for Windows (release 11.5; SPSS Inc, Chicago, Illinois, USA).

\section{RESULTS}

The number of babies born as singletons, twins, and higher order multiples in Oxfordshire and West Berkshire between 1970 and 1993 was 270 428, 6284, and 185 respectively. Of the 185 triplet and higher order multiple births, 20 were quadruplets. The rate of multiple births increased slightly over the time period in line with national trends.

Figure 1 illustrates the differential survival of babies born in multiple births. This shows Kaplan-Meier survival up to one year for singletons, twins, and higher order multiple births. Mortality was higher for twins and even greater for higher order multiple births, compared with singleton babies $\left(\log\right.$ rank test $\left.\chi^{2}=551.4, \mathrm{df}=2, \mathrm{p}<0.0001\right)$. Nevertheless, even among higher order multiple births, more than $90 \%$ of liveborn infants survived their first year.

As expected, most deaths occurred within the first month of life. Differences in survival decreased over time, and after about six months there were very few deaths.

Babies born in multiple births were at increased risk of both mortality and morbidity. The mean number of days in hospital up to age 5 for singletons, twins, and higher order multiple births respectively were seven, 15, and 30 (table 1). Relative rates, taking account of duration of life, show that twins experienced twice the number of days in hospital as singletons (relative rate $2.40,95 \%$ confidence interval 2.35 to 2.46), and triplets almost eight times as many days in hospital during the first five years of their lives (relative rate $7.58,95 \%$ confidence interval 6.60 to 8.69 ).

The lengthier periods of inpatient hospital care experienced by babies born in multiple births clearly have financial implications. Table 2 shows estimates based on mean specialty costs. In the birth admission and first year readmissions, the cost of inpatient hospital care increased significantly ( $p<0.0001$ ) with the multiplicity of birth. Relative to the cost of a singleton baby, the additional cost for

Table 1 Days in hospital up to age 5 by multiplicity of birth and relative rates accounting for duration of life

\begin{tabular}{lllllll}
\hline & Total number & No readmitted & Mean $(95 \% \mathrm{Cl})$ & Median (IQR) & Relative rate & $95 \% \mathrm{Cl}$ \\
\hline Singletons & 270428 & $126623(47 \%)$ & $7.1(7.0$ to 7.1$)$ & $5(4-7)$ & 1.00 & 2.35 to 2.46 \\
$\begin{array}{l}\text { Twins } \\
\text { Higher order }\end{array}$ & 6284 & $3137(50 \%)$ & $14.7(14.2$ to 15.3$)$ & $8(6-15)$ & 2.40 & 6.60 to 8.69 \\
multiple births & 185 & $92(50 \%)$ & $30.2(25.6$ to 34.8$)$ & $20(9-39)$ & 7.58 & \\
\hline
\end{tabular}


Table 2 Mean cost of hospital inpatient stay by multiplicity

\begin{tabular}{|c|c|c|c|c|c|c|c|c|c|c|}
\hline \multirow[b]{2}{*}{ Age at admission* } & \multicolumn{3}{|c|}{ Singletons } & \multicolumn{3}{|l|}{ Twins } & \multicolumn{3}{|c|}{ Higher order multiple births } & \multirow[b]{2}{*}{ p Valuet } \\
\hline & $\begin{array}{l}\text { Mean } \\
\text { costs }\end{array}$ & $95 \% \mathrm{Cl}$ & $\begin{array}{l}\text { No of } \\
\text { children }\end{array}$ & $\begin{array}{l}\text { Mean } \\
\text { costs }\end{array}$ & $95 \% \mathrm{Cl}$ & $\begin{array}{l}\text { No of } \\
\text { children }\end{array}$ & $\begin{array}{l}\text { Mean } \\
\text { costs }\end{array}$ & $95 \% \mathrm{Cl}$ & $\begin{array}{l}\text { No of } \\
\text { children }\end{array}$ & \\
\hline Initial birth admission & 846 & 841 to 850 & 270428 & 1931 & 1874 to 1987 & 6284 & 3678 & 3085 to 4271 & 185 & $<0.0001$ \\
\hline Readmissions starting in: & & & & & & & & & & \\
\hline lst year & 414 & 403 to 427 & 269596 & 1662 & 1541 to 1784 & 6163 & 4157 & 3189 to 5125 & 173 & $<0.0001$ \\
\hline 2nd year & 104 & 101 to 107 & 268318 & 119 & 94 to 145 & 6092 & 54 & 1 to 107 & 167 & 0.30 \\
\hline $3 r d$ year & 74 & 71 to 77 & 268184 & 80 & 63 to 97 & 6088 & 504 & 47 to 960 & 167 & $<0.0001$ \\
\hline 4 th year & 67 & 64 to 70 & 268099 & 71 & 58 to 85 & 6088 & 30 & 3 to 57 & 167 & 0.74 \\
\hline 5 th year & 65 & 62 to 68 & 268034 & 49 & 41 to 56 & 6085 & 135 & 0 to 289 & 167 & 0.088 \\
\hline Entire study period $\ddagger$ & 1532 & 1516 to 1548 & 270428 & 3826 & 3724 to 3929 & 6284 & 8156 & 7559 to 8754 & 185 & $<0.0001$ \\
\hline
\end{tabular}

Mean costs are per child in $£$ sterling.

*Only children alive at the start of the period were included in the cost estimates.

†Singletons, twins, and higher order multiple births were compared using multiple linear regression.

† Mean costs were adjusted for duration of life as a categorical variable grouped in 0-7 days, 8-28 days, 29-365 days, and 366-1825 days.

a twin was $£ 2294$ over the first five years. For a baby born in a higher order multiple birth, the additional cost was £6624. Annual costs decreased as the children got older, and cost differences between singletons and multiples tended to decrease. At ages 2-5 years, there was no significant variation by multiplicity except during the third year of life when higher order multiple births had significantly higher inpatient hospital costs. This was largely explained by the admission to hospital of one set of triplets who required considerable inpatient support.

\section{DISCUSSION}

This study shows the increased hospital inpatient costs associated with twins and higher order multiple births during the first five years of life. This is in line with work by others, including Keith et al ${ }^{17}$ and Callahan and Greene, ${ }^{18}$ who also reported increased costs associated with multiple births. Keith $\mathrm{et} \mathrm{al} \mathrm{l}^{17}$ reported that costs associated with neonatal care were $\$ 3600, \$ 8336$, and $\$ 60,045$ per baby (price date not reported) for singletons, twins, and triplets respectively. Callahan and Greene ${ }^{18}$ reported that the proportion of babies requiring treatment in neonatal intensive care were 15\%, $48 \%$, and $78 \%$ for singletons, twins, and triplets respectively, but that mean lengths of stay in neonatal intensive care were not significantly different.

The strength of this study is that it is based on a very large, geographically determined, dataset, which included data on all inpatient and day case admissions to NHS hospitals within the former Oxford Region over a 24 year period. However, it does not include data on outpatient or community health service costs or non-health related costs, such as social service or education related costs. The Mersey study of low birthweight babies found that costs in all these sectors were also increased when compared with normal weight babies $^{19}$, and this is also likely to be the case with low birthweight multiples. The use of health service resources is also greater in mothers of multiples both antenatally and postnatally, although these figures are dwarfed by the costs of neonatal care. ${ }^{78}$ None of these data give any measure of the intangible costs associated with multiple gestation pregnancies and births.

Although the current study is unusual in covering a five year time frame, the corollary of this is that the data on births are not current; the most recent year of hospital data available from ORLS was 1998, the latest births therefore were in 1993. Practice may have changed in the intervening decade.

The ORLS included all admissions to NHS hospitals in the area covered by the former Oxford Region. Migration out of this area was estimated at $2.5 \%$ per year among the $0-15$ age group..$^{20}$ This would result in under-reporting of the absolute levels of resource use and costs. However, there is no evidence that migration varies by multiplicity of birth, and therefore the cost differences between groups should be robust even if the absolute costs are an underestimate.

It is likely that a large proportion of the triplets and higher order multiple births were conceived with the aid of in vitro fertilisation, a procedure that has become more common in the last few decades. Monitoring of assisted reproductive techniques is carried out by the Human Fertilisation and Embryology Authority in the United Kingdom. The latter has recently ruled that not more than two embryos be replaced during in vitro fertilisation for women aged under 40 years and not more than three in older women. ${ }^{21}$ The recommendation to this effect, before the ruling, may have already reduced the number of multiple births and associated costs to the NHS, although it is not clear what proportion of multiple births are due to embryo transfer and what proportion are due to ovarian stimulation, which may be prescribed by general practitioners as well as specialists.

This study shows the vast differences in use of hospital inpatient resources and costs associated with twins, triplets, and higher order multiple births compared with singletons during the first five years of life. These costs are only one part of the picture. A systematic review of the economic implications of prematurity and low birth weight, including babies born in multiple births, found that costs of caring for these children were higher in the community, in social services, and education; costs to the families were also greater. ${ }^{11}$

\section{What is already known on this topic}

- Babies born in multiple births are more likely to be born preterm and at low birth weight.

- Short term health service costs associated with multiple births are higher than for singletons.

\section{What this study adds}

- Mean total number of days in hospital up to age 5 increases steeply with multiplicity of birth.

- Health service costs up to age 5 likewise increase steeply with multiplicity.

- The greatest component of total costs, and the greatest difference in costs, occurs in the first year of life. 
There is scope for more in-depth research into the costs borne by families, including intangible costs, associated with multiple births. Policy implications of increasing provision of assisted reproductive techniques, and in vitro fertilisation in particular, need to be assessed. Draft guidelines from the National Institute for Clinical Excellence (NICE) propose recommending that, for couples meeting certain criteria, up to three cycles of in vitro fertilisation be paid for by the NHS. ${ }^{22}$ This would address some of the problems of the "postcode lottery" but would work against local decision making. If the draft guidelines are agreed, it would be important to evaluate outcomes from clinical, psychological, and health economic perspectives.

\section{ACKNOWLEDGEMENTS}

This study was supported by a Wellcome Trust Health Services Research grant (ref 068516/Z/02/Z). The National Perinatal Epidemiology Unit is core funded by the Department of Health. Data collection for the ORLS was funded by the former Oxford Regional Health Authority. The Unit of Health Care Epidemiology is funded by the Department of Health and Social Care (South). The views expressed by the authors do not necessarily reflect those of the funding bodies. Ziyah Mehta (formerly of the NPEU) helped enormously with the statistical analysis of these data. Paula CookMozaffari conducted the data extraction from the ORLS data.

\section{Authors' affiliations}

J Henderson, C Hockley, S Petrou, National Perinatal Epidemiology Unit, Old Road Campus, University of Oxford, Oxford OX3 7LF, UK M Goldacre, Unit of Health Care Epidemiology, Old Road Campus, University of Oxford

L Davidson, Department of Population and Family Health, Columbia University, New York, NY 10032, USA

\section{REFERENCES}

1 Dunn A, Macfarlane A. Recent trends in the incidence of multiple births and associated mortality in England and Wales. Arch Dis Child 1996;75:F10-19.

2 Keith L, Blickstein I. Triplet pregnancies and their consequences. Lancaster: Parthenon, 2002.
3 Blondel B, Macfarlane A. Rising multiple maternity rates and medical management of subfertility. Eur J Public Health 2003;13:83-6.

4 Papiernik E. Social costs of twin births. Acta Genet Med Gemellol (Roma) 1983:32:105-11.

5 Callahan TL, Hall JE, Ettner SL, et al. The economic impact of multiple-gestation pregnancies and contribution of assisted-reproductive techniques to their incidence. N Engl J Med 1994;331:244-9.

6 Mugford M, Henderson J. Resource implications of multiple births. In: Ward RH, Wittle M, eds. Multiple pregnancy. London: RCOG Press, 1995.

7 Chelmow D, Penzias AS, Kaufman G, et al. Costs of triplet pregnancy. Am J Obstet Gynecol 1995; 172:677-82.

8 Malone FD, Chelmow D, Athanassiou A, et al. Impact of gestational age at delivery on the economics of triplet pregnancy. $J$ Maternal Fetal Med 1999;8:256-61.

9 Petrou S, Davidson LL. Economic issues in the follow-up of neonates. Semin Neonatol 2000;5:159-69.

10 Petrou S, Mugford M. Predicting the costs of neonatal care. In: Hansen TN, Mclntosh N, eds. Current topics in neonatology. London: WB Saunders, 2000:4:149-74.

11 Petrou S, Sach T, Davidson LL. The long-term costs of preterm birth: results of a systematic review. Child Care Health Dev 2001;27:97-115.

12 Petrou S, Mehta Z, Hockley C, et al. The impact of preterm birth on hospital inpatient admissions and costs during the first five years of life. Pediatrics 2004; in press.

13 Goldacre MJ, Simmons H, Henderson J, et al. Trends in episode based and person based rates of admission to hospital in the Oxford record linkage study area. BMJ 1988;296:583-4.

14 Netten A, Curtis L. Unit costs of health and social care 2002. http:// www.pssru.ac.uk/UC2002.htm

15 Agresti A. Categorical data analysis. New York: John Wiley \& Sons, 1990.

16 Barber JA, Thompson SG. Analysis of cost data in randomized trials: an application of the non-parametric bootstrap. Stat Med 2000;19:3219-36.

17 Keith LG, Papiernik, Luke B. The costs of multiple pregnancy. Int J Gynaecol Obstet 1991;36:109-14.

18 Callahan TL, Greene MF. The economic impact of multiple gestation. Infertility and Reproductive Medical Clinics of North America 1998;9:513-25.

19 Stevenson RC, McCabe CJ, Pharoah PO, et al. Cost of care for a geographically determined population of low birthweight infants to age 8-9 years. I. Children without disability. Arch Dis Child Fetal Neonatal Ed 1996;74:F114-17.

20 Jones ME, Swerdlow AJ. Bias caused by migration in case control studies of prenatal risk factors for childhood and adult diseases. Am J Epidemiol 1996;143:823-31.

21 Human Fertilisation and Embryology Authority. Code of practice. http:// www.hfea.gov.uk.

22 National Institute for Clinical Excellence. Fertility: assessment and treatment for people with fertility problems. NICE guidelines, second draft for consultation. London: National Institute for Clinical Excellence, 2003. 